\title{
Analysis and implementation of LLC-T series parallel resonant converter using fuzzy logic controller
}

\author{
C. Nagarajan ${ }^{1 *}$, M. Madheswaran ${ }^{2}$ \\ ${ }^{1}$ Bharath University, Chennai. Tamilnadu, INDIA \\ ${ }^{2}$ Centre for Advanced Research, Muthayammal Engineering College, Rasipuram, Tamilnadu, INDIA. \\ "Corresponding Author: e-mail: nagaraj2k1@gmail.com, Tel +91-9894620123,
}

\begin{abstract}
A modified LLC-T (inductor inductor capacitor) series parallel resonant converter (SPRC) has been simulated and the performance is analyzed. The limitations of two element resonant topologies have been removed by adding a third reactive element. The output voltage is regulated using fuzzy logic controller. The simulation study indicates the superiority of fuzzy control over the conventional control methods. The proposed approach is expected to provide better voltage regulation for dynamic load conditions. A prototype $300 \mathrm{~W}, 100 \mathrm{kHz}$ converter is designed and built to experimentally demonstrate, dynamic and steady state performance for the LLC-T series parallel resonant converter. A comparative study is performed between experimental results and the simulation studies. The analysis shows that the output of converter is free from the ripples, and has constant current, regulated output voltage.
\end{abstract}

Keywords: Resonant Converter, Fuzzy Logic, Control System, Power Electronics, MATLAB.

\section{Introduction}

The design and development of various DC-DC resonant converters (RC) have been focused for telecommunication and aerospace applications in the recent past year, it has been found that these converters experience high switching losses, reduced reliability, electromagnetic interference (EMI) and acoustic noise at high frequencies. The LCL tank circuit based DC-DC converter have been experimentally demonstrated and reported in Raju and Doradla (1995) and Bhat (1994a, 1997). It has been found from the literature that the LCL tank circuit has been connected in series with the load and operated in above resonant frequency. It is also observed that the series parallel resonant converter improves the load efficiency (Bhat, 1993, 1994b). Later, Borage et al. (2005) have demonstrated an LCL-T half bridge resonant converter with clamp diodes, in which the output voltage of constant current power supply increases linearly. Therefore a constant-voltage limit must be incorporated in the converter. In order to get these operations the clamp diode is required. Borage et al. (2009) have demonstrated the characteristics of LCL-T Resonant converter using Asymmetrical duty cycle (ADC). The converter operated at fixed resonant frequency and its analyzed using state space approach. Belaguli and Bhat (2000) have experimentally demonstrated with independent load when operated at resonant frequency, making it attractive for application as a constant voltage (CV) power supply. It has been found from the literature that the LCL tank circuit connected in series-parallel with the load and operated in above resonant frequency improves the load efficiency and independent operation. China and Sng (2009) have demonstrated LCC series parallel resonant converter using robust control method, the converter gain was derived by using the state plan analysis. The voltage and current type load was presented with variable load condition. The closed loop operation was presented using PI controller with load independent operation as obtained.

Later, Gu et al. (2005) investigated LLC topology in detail using fundamental approximation, but simplified the AC equivalent circuit by ignoring the leakage inductance in the secondary side. Lu et al. (2006) have demonstrated LLC resonant converter, the performance of controller has been evaluated and found that the load independent operation may not be possible. Nagarajan and Madheswaran (2010) have simulated an LCL-T series parallel resonant converter using fuzzy logic controller and PID controller. The performance of the controller has been presented. The fuzzy logic controller was found to have better performance compared 
to the PID controller. The harmonic spectrum and dynamic analysis fed RLE load was presented. Prabhakar et al. (2009) have simulated an LCC resonant converter. The voltage gain expressions are derived for different resonant topologies. Here the load variation and load independent operation was not presented and there was no static and dynamic analysis.

It is clear from the literature studies that the output voltage regulation of the converter against load and supply voltage fluctuations have important role in designing high-density power supplies. In the proposed LLC-T series parallel resonant converter is operating in constant output current and constant output voltage is presented. The series capacitor limits the circulating current. Therefore the clamping diodes are not necessary which reduces the circuit complexity. It reduces the component stress, there by it is easily paralleling to the other converter with current sharing. The closed loop module and AC analysis has been derived and simulate using MATLAB/Simulink. A prototype $300 \mathrm{~W}, 100 \mathrm{kHz}$ the LLC-T series parallel resonant converter is implemented and the experiment results are compared with the simulation results. The simulation results agree with the experimental results.

\section{Proposed LLC-T Series Parallel Resonant Converter}

The circuit diagram of the LLC-T series parallel resonant converter with capacitive and inductive output filter is shown in Figure 1. The resonant tank consisting of three reactive energy storage elements (LLC) has overcome the conventional resonant converter that has only two elements. The first stage converts a dc voltage to a high frequency ac voltage. The second stage of the converter is to convert the ac power to dc power by suitable high frequency rectifier and filter circuit. Power from the resonant circuit is taken either through a transformer in series with the resonant circuit (or) series in the capacitor comprising the resonant circuit as shown in Figure 1. In both the cases the high frequency feature of the link allows the use of a high frequency transformer to provide voltage transformation and ohmic isolation between the dc source and the load.

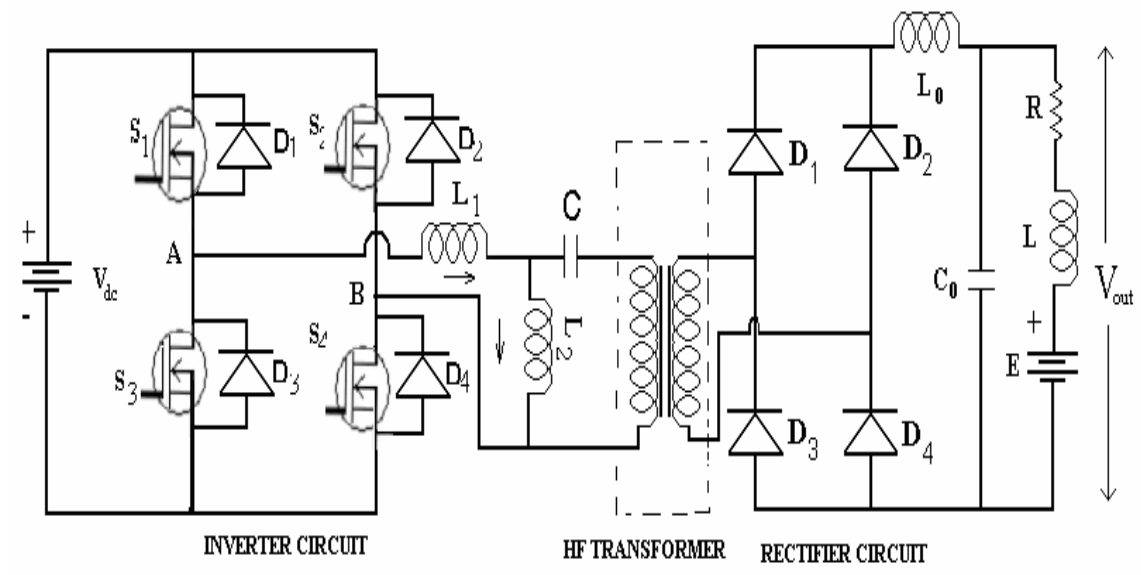

Figure 1. LLC-T series parallel resonant converter circuit

In LLC-T series parallel resonant converter the load voltage can be controlled by varying the switching frequency or by varying the phase difference between the inverter. The phase domain control scheme is suitable for wide variation of load condition because the output voltage is independent of load. The dc current is absent in the primary side of the transformer, there is no possibility of current balancing. Another advantage of this circuit is that the device currents are proportional to the load current. This increases the efficiency of the converter at light loads to some extent because the device losses also decrease with the load current. If the load gets short circuited at this condition, very large current would flow through the circuit. This may damage the switching devices. To make the circuit short circuit proof the operating frequency should be changed.

\section{AC Analysis of the Proposed LLC-T Series Parallel Resonant Converter}

In the ac analysis, the output rectifier and filter are replaced by the equivalent ac resistance and the square-wave input voltage source is replaced by its fundamental sinusoidal equivalent. The power transfer from input to output is assumed to be only via the fundamental component and the contribution of all the harmonics is neglected. Without losing generality, the turn's ratio $\left(\mathrm{N}_{1} / \mathrm{N}_{2}\right)$ of the isolation transformer $\mathrm{n} \times 1$ is assumed to be unity. The equivalent circuit for LLC-T series parallel resonant converter is shown in Figure 2.The output power is associated to the output load resistance Ro. $R_{a c}$ is the ratio of the instantaneous voltage and current.

$$
\begin{gathered}
\mathrm{I}_{\mathrm{orms}}{ }^{2} \mathrm{R}_{\mathrm{ac}}=\mathrm{I}_{\mathrm{dc}}{ }^{2} \mathrm{R}_{\mathrm{o} .,} \quad \frac{V_{o a c}^{2}}{R_{a c}^{2}} R_{a c}=\frac{V_{d c}^{2}}{R_{o}{ }^{2}} R_{o} \\
R_{a c}=\frac{8}{\pi^{2}} R_{o}
\end{gathered}
$$


Transfer Function:

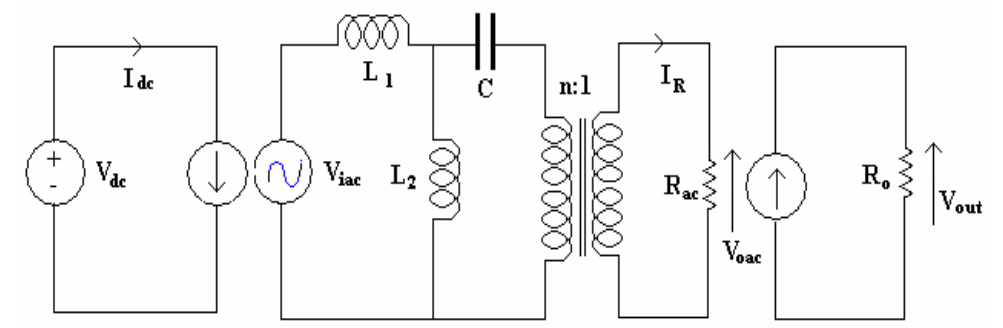

Figure 2. Equivalent circuit for LLC-T series parallel resonant converter

The ac resonant tank can be defined by the following transfer function $\mathrm{H}(\mathrm{s})$.

$H(s)=\frac{1}{n} \frac{\left(\frac{1}{s C}+n^{2} R_{a c}\right) s L_{2}}{s L_{1}\left(\frac{1}{s C}+n^{2} R_{a c}+s L_{2}\right)+\left(\frac{1}{s}+n^{2} R_{a c}\right) s L_{2}}$

Voltage gain:

$$
\frac{V_{\text {out }}}{V_{\text {dc }}}=\frac{1}{2 n} M
$$

From the above equation the voltage and current gain of LLC-T series parallel resonant converter can be derived as

$$
\begin{aligned}
& M=\frac{V_{o}}{V_{\text {in }}}=\frac{1}{\left(\frac{1+\delta}{\delta}\right)+j \frac{\pi^{2}}{8} Q\left(\omega_{n}-\frac{1}{\omega_{n}}(\delta+1)\right)} \\
& H=\frac{1}{\frac{1}{Q}\left(\frac{1+\delta}{\delta}\right)+j \frac{\pi^{2}}{8}\left(\omega_{n}-\frac{1}{\omega_{n}}(\delta+1)\right)}
\end{aligned}
$$

The voltage conversion ratio is equal to one half the module of resonant tank. The resonant frequency and normalized switching frequency are defined as

$$
\omega_{r}=\frac{1}{\sqrt{L C}}, \quad f_{r}=\frac{1}{2 \pi \sqrt{L C}}, \omega_{n}=\frac{\omega_{s}}{\omega_{r}}, f_{n}=\frac{f_{s}}{f_{r}} .
$$

Quality factor: $\quad Q=\frac{Z_{\text {in }}}{R_{\text {ac }}}=\frac{\pi^{2} Z_{o} P_{\text {out }}}{8 n^{2} V_{\text {out }}^{2}}$

Induction ratio: $\delta=\frac{L_{1}}{L_{2}}$

The characteristic impedance: $Z_{o}=\sqrt{\frac{L_{1}}{C}}=2 \pi f_{r} L_{r}=\frac{1}{2 \pi f_{r} C}$

\section{Results and Discussion}

\subsection{Design parameters of the converter}

For the design of LLC-T series parallel resonant converter (Borage et al., 2009), the design specifications are minimum and maximum value of dc voltage, maximum output current $\left(I_{\mathrm{o}}\right)$, corresponding to the full-load condition and switching frequency $\left(f_{s}\right)$. In the analysis of previous sections, the transformer turns ratio $\left(N_{1} / N_{2}\right)$ was assumed to be unity. It is desired to design the converter with the following specifications:

The values used for all the elements are presented. These values were obtained using a design procedure (Borage et al., 2009) to assure resonance for almost different power ranges (load-independent design) and also to limit the current and voltage peak values. The fuzzy controller used is robust to parameter variations as well as for a wide load operating conditions. The simulation and implementation are carried out for $300 \mathrm{~W}$ load power. The load used on the tests is composed of a series connection of a resistor and a small inductor. 
Table.1.Design Parameters

\begin{tabular}{|l|l|l|}
\hline S.No & \multicolumn{1}{|c|}{ Parameter } & \multicolumn{1}{c|}{ Value } \\
\hline 1 & Power output & $300 \mathrm{~W}$ \\
\hline 2 & Minimum input voltage & $100 \mathrm{~V}$ \\
\hline 3 & Minimum output voltage & $100 \mathrm{~V}$ \\
\hline 4 & Maximum load current & $3 \mathrm{~A}$ \\
\hline 5 & Transformer Turns ratio & 1 \\
\hline 6 & Switching frequency $\left(\mathrm{f}_{\mathrm{s}}\right)$ & $100 \mathrm{KHz}$ \\
\hline 7 & Series Inductance $\mathrm{L}_{1}, \mathrm{~L} 2$ & $39.18 \mu \mathrm{H}$ \\
\hline 8 & Parallel Capacitance $(\mathrm{C})$ & $66 \mathrm{nF}$ \\
\hline 9 & Load Inductance $\left(\mathrm{L}_{\mathrm{o}}\right)$ & $1 \mathrm{mH}$ \\
\hline 10 & Load Capacitance $\left(\mathrm{C}_{\mathrm{o}}\right)$ & $650 \mu \mathrm{F}$ \\
\hline
\end{tabular}

\subsection{Fuzzy Logic Control (FLC)}

Fuzzy control involves three stages: fuzzification, inference or rule evaluation and defuzzification. Series parallel resonant converter is modeled using MATLAB software. Fuzzy control is developed using the fuzzy toolbox. Five triangular membership functions are chosen for simplicity. Table 2 shows the fuzzy rule base created in the present work based on intuitive reasoning and experience. Fuzzy memberships NB, NS, Z, PS, PB are defined as negative big, negative small, zero, positive small, and positive big.

Table.2.Fuzzy Rules

\begin{tabular}{|c|c|c|c|c|c|c|}
\hline \multicolumn{7}{|c|}{ Error (e) } \\
\hline \multirow{6}{*}{ 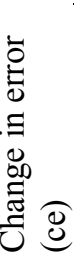 } & \multicolumn{6}{|c|}{ (1) } \\
\hline & $\stackrel{2}{n}$ & NB & NB & \multirow{2}{*}{$\frac{\mathrm{NB}}{\mathrm{NS}}$} & \multirow{2}{*}{ NM } & \multirow{2}{*}{$\begin{array}{l}\mathrm{Z} \\
\mathrm{PM}\end{array}$} \\
\hline & \multirow{2}{*}{\begin{tabular}{|l|}
$\mathrm{NS}$ \\
$\mathrm{Z}$ \\
\end{tabular}} & NB & NM & & & \\
\hline & & NB & NS & $Z$ & PS & PB \\
\hline & PS & NM & Z & PS & PM & \multirow{2}{*}{$\begin{array}{l}\mathrm{PB} \\
\mathrm{PB}\end{array}$} \\
\hline & PB & $\mathrm{Z}$ & PM & PB & PB & \\
\hline
\end{tabular}

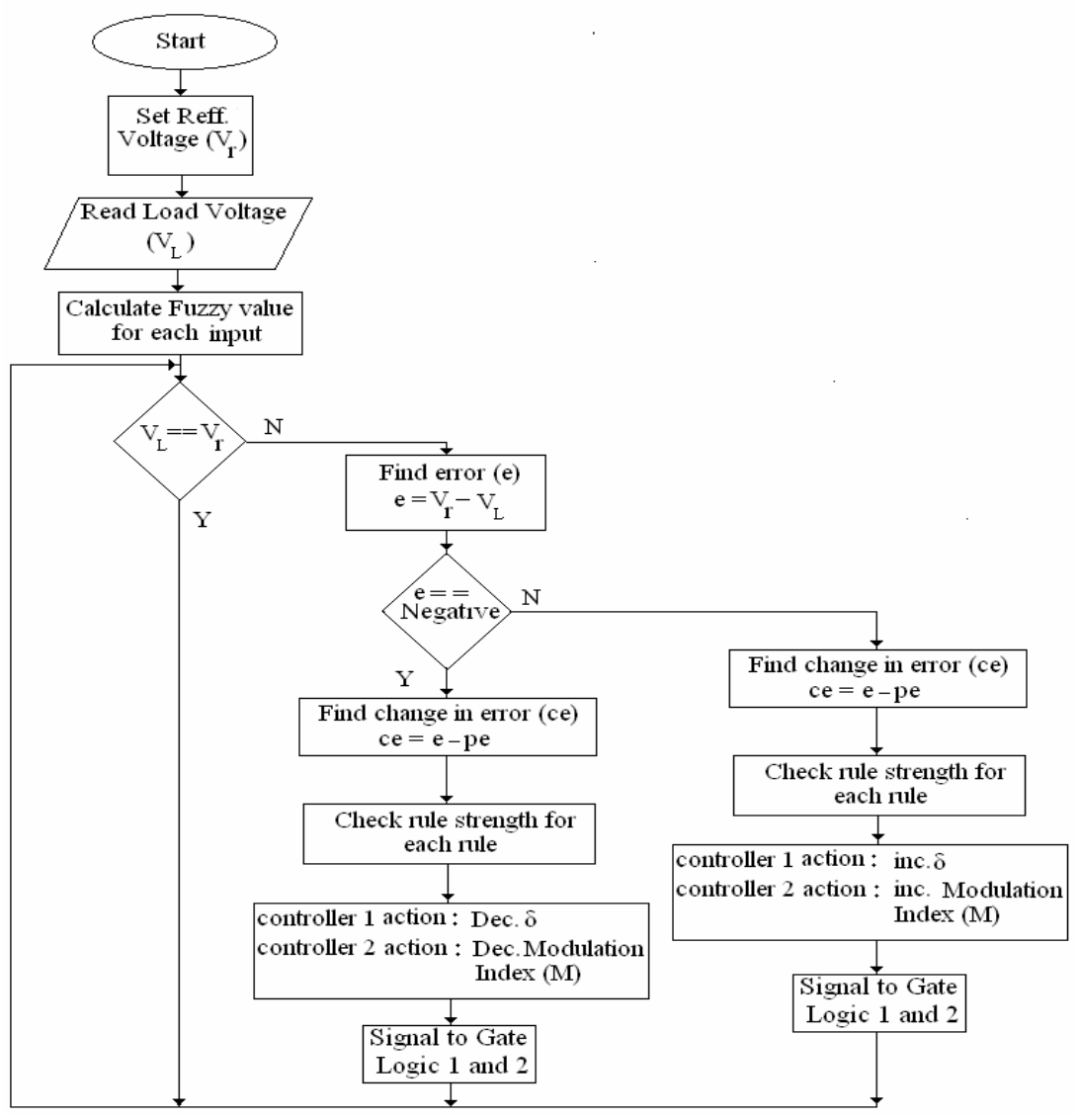

Figure 3. Flowchart for the FLC 
Where $\mathrm{V}_{\mathrm{r}}$ is the reference or the desired output voltage, $\mathrm{V}_{\mathrm{L}}$ is the actual output voltage and pe is previous error. If the output voltage continues to increase gradually while the current is low during the charging process the fuzzy controller will maintain increase in voltage to reach the set point. A drop in the output voltage level triggers the fuzzy controller to increase the output voltage of the converter by modifying the Modulation Index (MI) of the converter. The resolution of fuzzy logic control system (Figure 3) relies on the fuzziness of the control variables while the fuzziness of the control variables depends on the fuzziness of their membership functions.

\subsection{Simulation Results}

The closed loop simulation using FLC is carried out using MATLAB/Simulink software. Depending on error and the change in error, the value of change of switching frequency is calculated. The fuzzy set parameters instruction and function blocks available in MATLAB are used to update the new switching frequency of the pulse generators. The entire system is simulated with a switching frequency of $100 \mathrm{KHz}$. The converter resonant voltage, resonant current and output load voltage are shown in Figure.4a$4 \mathrm{e}$.

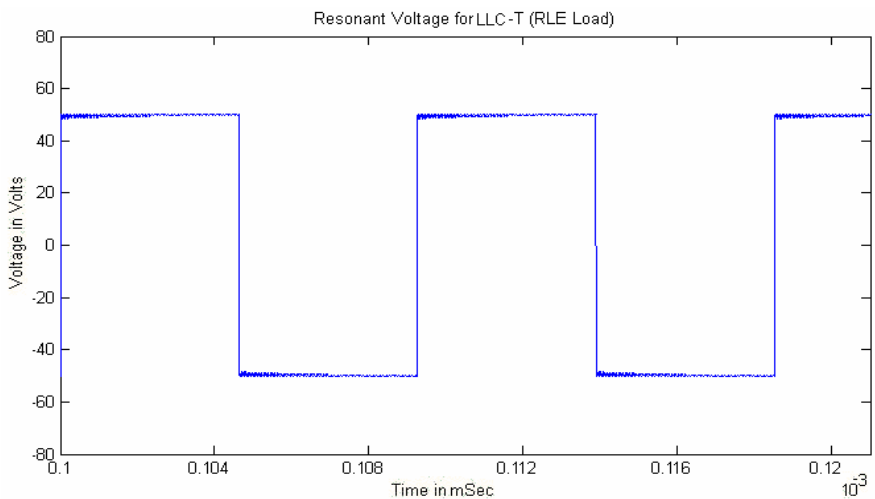

(a)

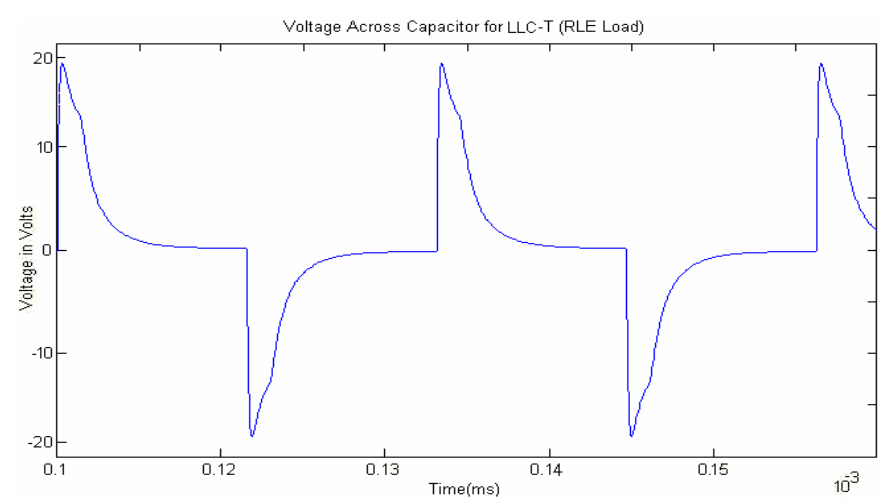

(c)

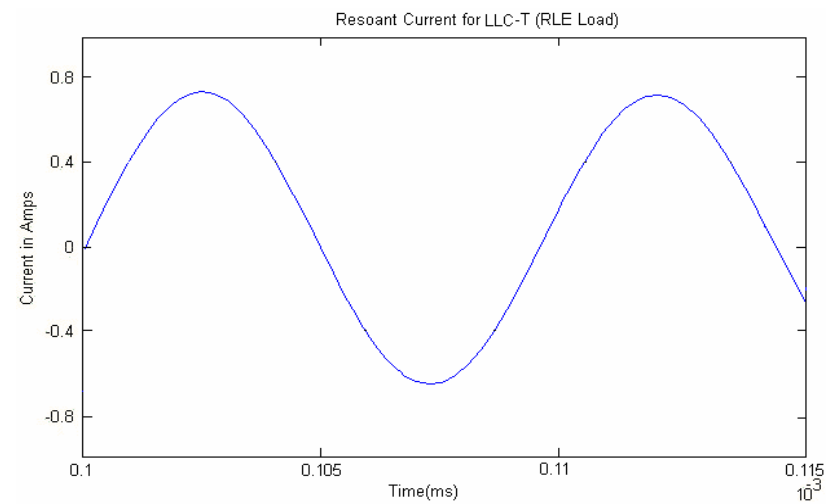

(b)

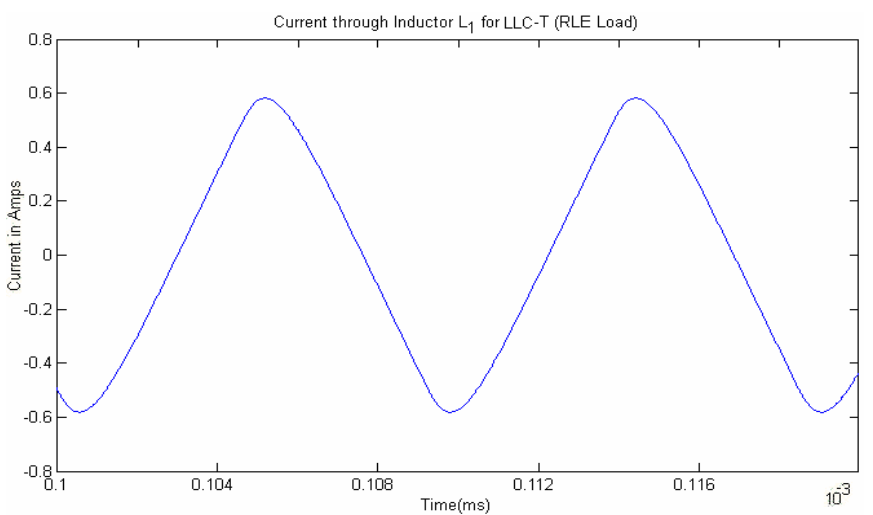

(d)

Cutput Voltage for RLE Load (LLC-T) using FLC

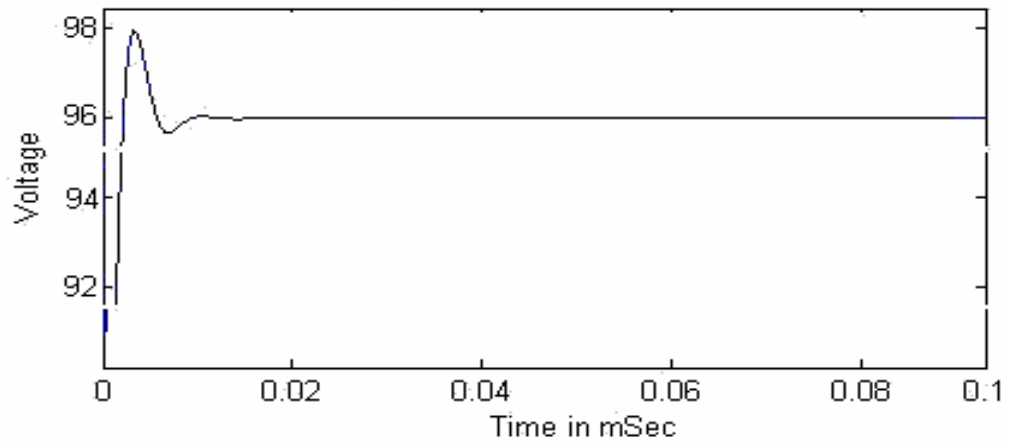

(e)

Figure 4. (a) Inverter Voltage $\left(\mathrm{V}_{\mathrm{AB}}\right)$, (b) Inverter Current (Transformer Primary side), (c) Voltage across Capacitor, (d) Current through Inductance $\mathrm{L}_{1}$, (e) Output voltage fed RLE load for $\mathrm{V}_{\mathrm{r}}=100 \mathrm{~V}$. 
It is observed that the settling time $0.025 \mathrm{sec}$. The slight droop in the resonant characteristics is due to the increase in conduction losses in the bridge inverter and resonant network. The output voltage response is flexible and sensitive. The integrator increases the system type number, thus minimizing the steady-state error. FLC help amplification of high frequency noise which is a serious drawback in switching converter applications. It is inferred that the measurement overshoot and noise is highly suppressed. The performance of LLC-T series parallel resonant converter response have been estimated and provided in Table 3 . This ensures that the system can be controlled effectively with feedback.

Table 3.Evaluation of Transient and Steady State performances by using FLC

\begin{tabular}{|l|c|c|c|}
\hline \multicolumn{1}{|c|}{ Controller } & Settling Time in Sec & $\%$ Over Shoot & $\begin{array}{c}\text { Steady state } \\
\text { error }\end{array}$ \\
\hline Open loop & 0.52 & 1.61 & 0.05 \\
\hline Closed Loop (FLC) & 0.025 & $1 \mathrm{~V}$ & 0.004 \\
\hline
\end{tabular}

It is clear from the above table shows that the peak overshoot is eliminated and the settling time is much lower with the fuzzy control strategy. The measurement noise is highly suppressed.

\subsection{Converter analysis}

These results are completely validated experimentally by plotting the variation of MI (modulation index) with normalized switching frequency $\mathrm{f}_{\mathrm{n}}$, shown in Figure 5 . The deviation increases with reducing values of load resistance or increasing values of load current for the given voltage. This arises because of sensing resistance of $0.5 \Omega$ used in series with the resonant element for monitoring and finite resistance is offered by diodes and MOSFET'S in conduction.

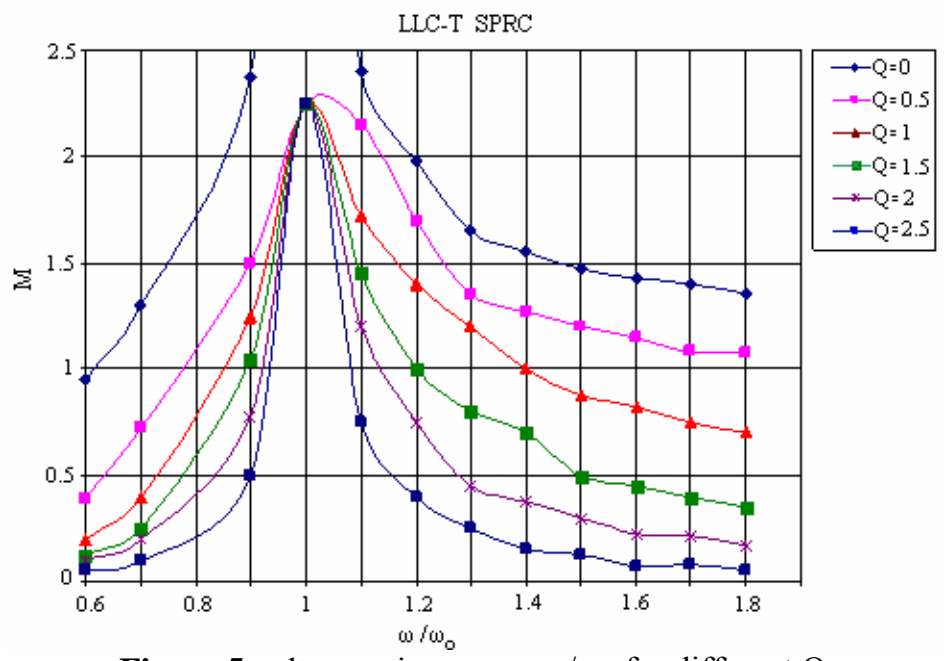

Figure 5.voltage gain versus $\omega_{\mathrm{s}} / \omega_{\mathrm{r}}$ for different $\mathrm{Q}$

In order to maintain the output voltage constant against the variations in the load resistance and the input voltage, the FLC has to be changed in a closed-loop manner. However, the required change in pulse width to maintain constant output voltage against load variations and constant input voltage is very small. The Figure 5.shows the voltage gains versus normalized switching frequency. For different values of $\mathrm{Q}$, it is clearly visible that the LLC resonant converter presents a load-independent operating point at the resonance frequency $f_{r}\left(f_{n}=1\right)$.

\section{Experimental results}

The LLC-T series parallel resonant converter is fabricated and tested. A prototype LLC-T series parallel resonant converter is operating at $300 \mathrm{~W}, 100 \mathrm{kHz}$ was designed. ATMAL microcontroller 89C51 is used to generate driving pulses, these pulses are amplified using the driver IC IR2110, the IRF840 MOSFETs are used as the switches in the bridge converter. The diodes MUR 4100 are used for the output bridge rectifier. It's clearly shown in figures that the power losses in the occurrence of the turn on switching are maintained very low by means of the resonant operation. The hardware module is shown in Figure.6.The Multi Storage Oscillogram (MSO) of inverter voltage, inverter current, voltage across parallel capacitor, current through inductance $\mathrm{L}_{1}$ and output voltage fed with the DC motor are shown in Figure.6. 


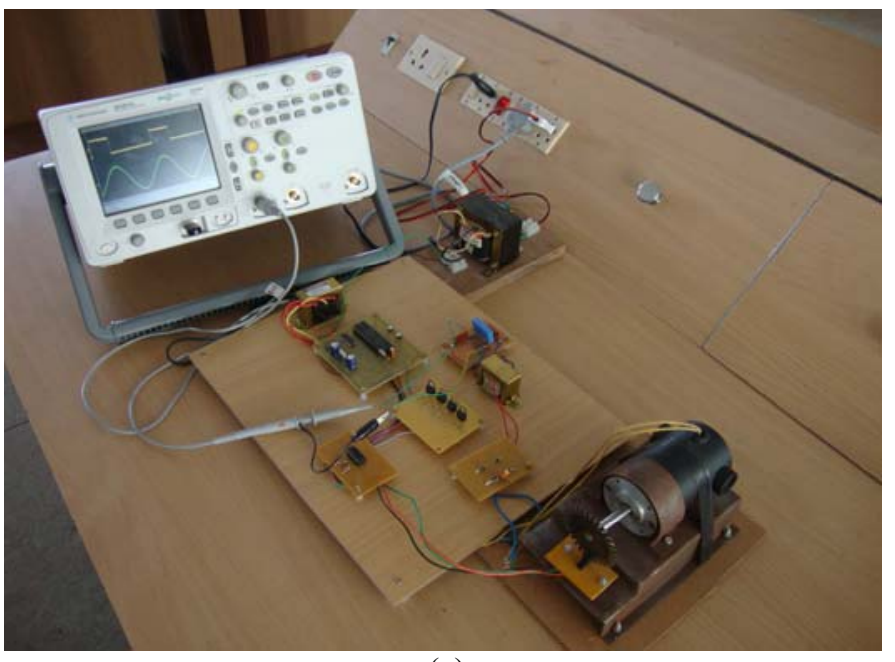

(a)

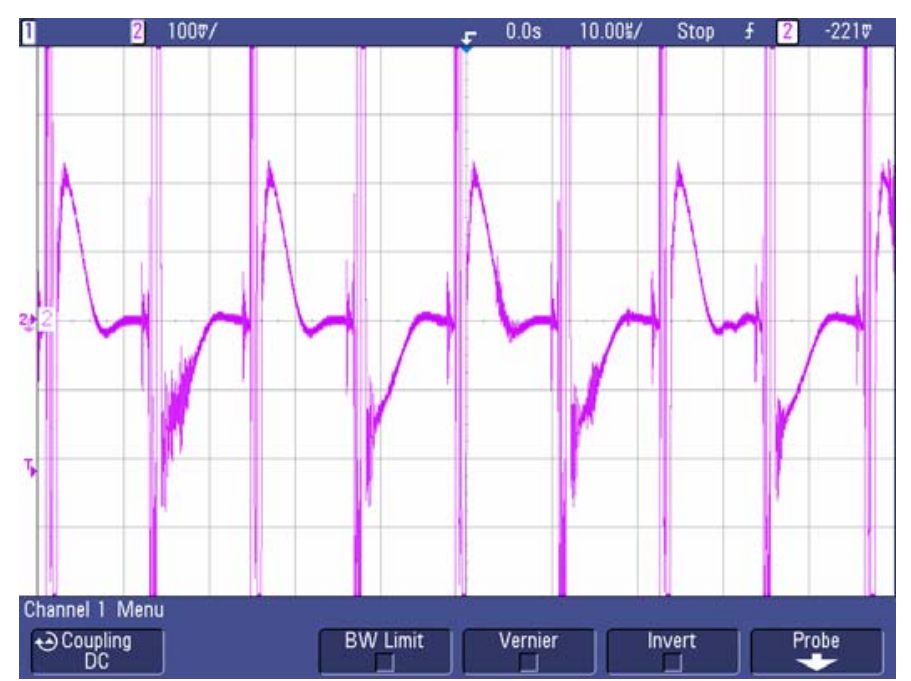

(c)

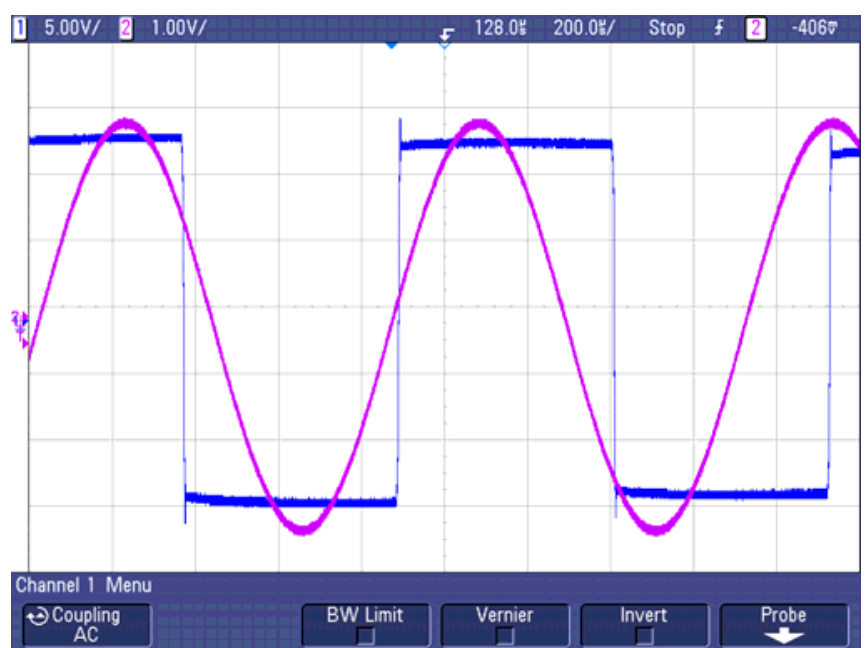

(b)

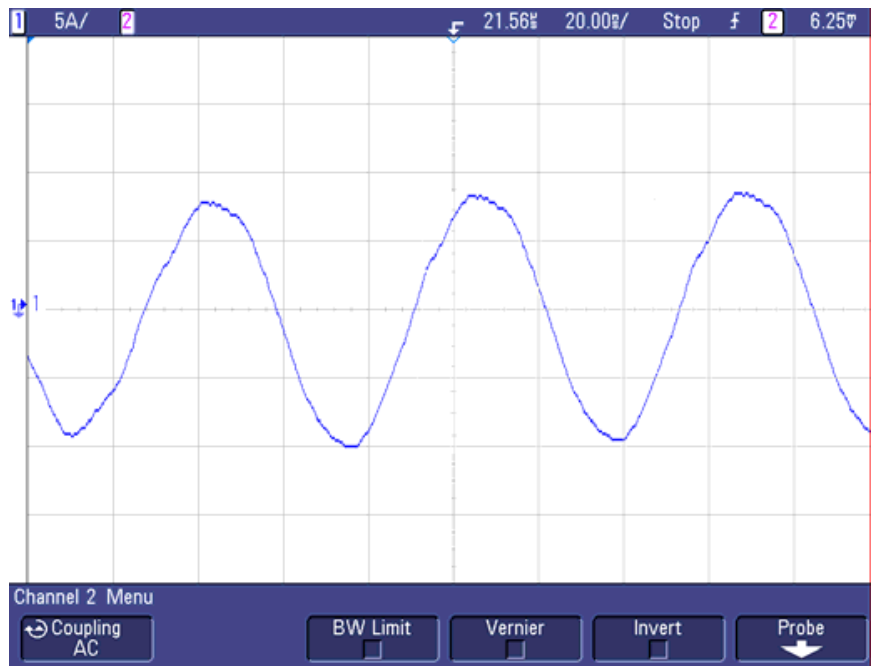

(d)

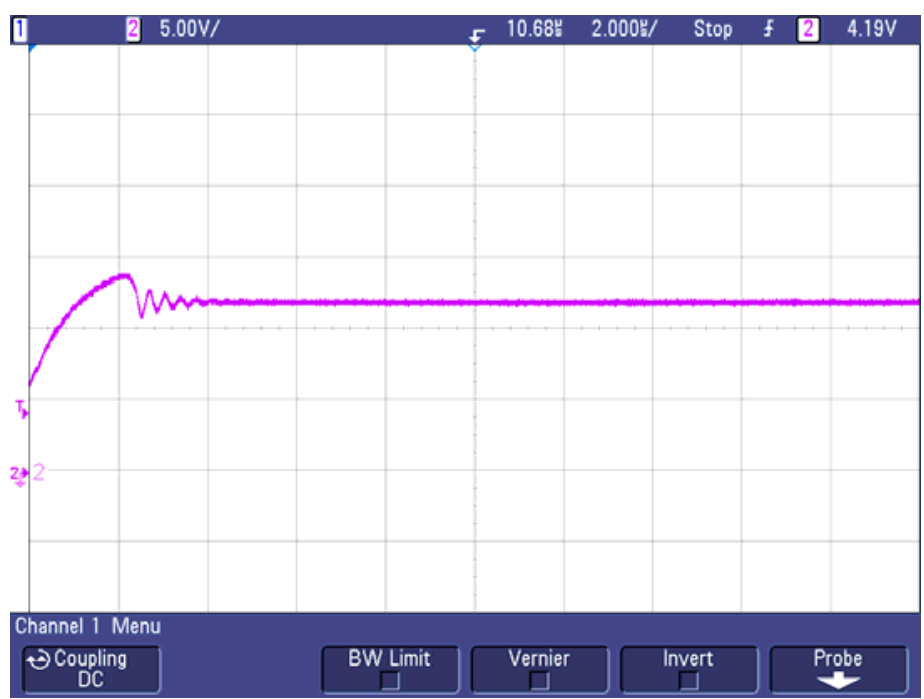

(e)

Figure 6.Experimental Waveforms for (a) Hardware module for LLC-T series parallel resonant converter (b) CH1: Resonant Voltage [Volt. Scale: 40 V/div.], CH2: Resonant Current [Amp. Scale: 0.5A/div.] (c) Voltage across the Capacitor [Volt. Scale: 20 V/div.] (d) Current through Series Inductor L 1 [Amp. Scale: 0.5A/div.] (e) Output Capacitor Voltage [Volt. Scale: 50 V/div.]. 
The above figures show the fuzzy controller output signal for this test. These figures show the good dynamic performance of the controller. The current and voltage response for the inductor and capacitor $\mathrm{C}$ and $\mathrm{L}_{1}$ are shown in Figure.6(c-d).The inductor and capacitor are connected to the output of inverter for resonance purpose and it is used for impedance matching, current control. Another good feature of this converter is that the converter operation is not affected by the non idealities of the output transformer (magnetizing inductance) because of the additional resonance inductor $\mathrm{L}_{2}$. The output voltage is constant for any load variation. Figure.6 (e) the figure shows the good performance of the whole design. One can conclude that the controller is capable of operating under load- independent operation, again, it can be seen that the output follows the reference with good accuracy and better dynamic performances. The LLC-T series parallel resonant converter is verified by simulation and experimental studies. It is proved from the performance Table 4, the experimental results shows the control characteristics are observed to closely match the theoretical values, and the output Voltage is seen to be nearly independent of load.

Table 4.Performance measures of Theoretical \& Simulation Results for LLC-T series parallel resonant converter fed RLE Load

\begin{tabular}{|l|c|c|c|c|}
\hline \multirow{2}{*}{ Performance measures } & $\begin{array}{c}\text { Simulation } \\
\text { Studies }\end{array}$ & $\begin{array}{c}\text { Experimental } \\
\text { Studies }\end{array}$ & \begin{tabular}{c} 
Simulation \\
Studies \\
\cline { 2 - 5 }
\end{tabular} & \multicolumn{2}{|c|}{ Open loop control } & $\begin{array}{c}\text { Experimental } \\
\text { Studies }\end{array}$ \\
\hline Load Voltage in Volts & 99 & 95.3 & 99 & 97.5 \\
\hline Load Current in Amps & 1.6 & 2.1 & 1.8 & 1.96 \\
\hline Settling Time in sec. & 0.52 & 1.6 & 0.025 & 0.03 \\
\hline$\%$ Over Shoot & 1.8 & 2.6 & 1 & 1.2 \\
\hline Steady state error & 0.05 & 2 & 0.004 & 0.004 \\
\hline
\end{tabular}

The output power for various input power and output power has been shown in Figure.7 (a). It is observed that the power drawn decays steeply for lower load and as the load increases the power drawn decreases gradually and remains constant at greater loads. It is also seen that the proposed new control strategy has less load Sensitivity. The results obtained indicate that the FLC based LLC-T series parallel resonant converter is an effective approach for DC-DC converter output voltage regulation.

Input Power Vs Output Power

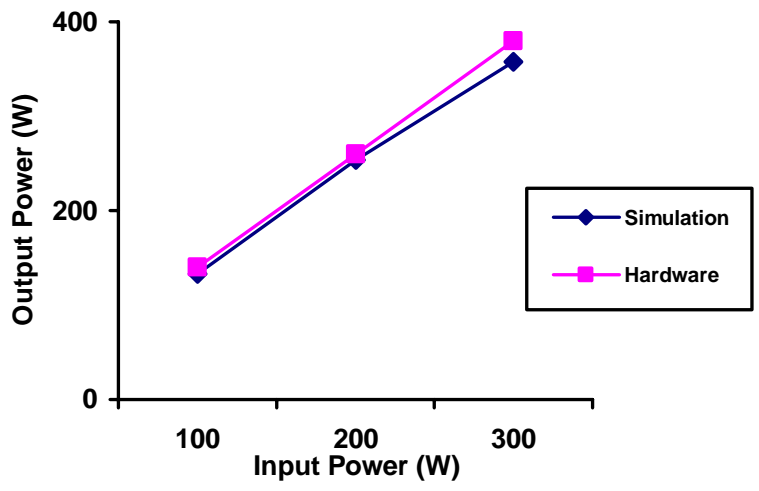

(a)
Output Power Vs Efficiency

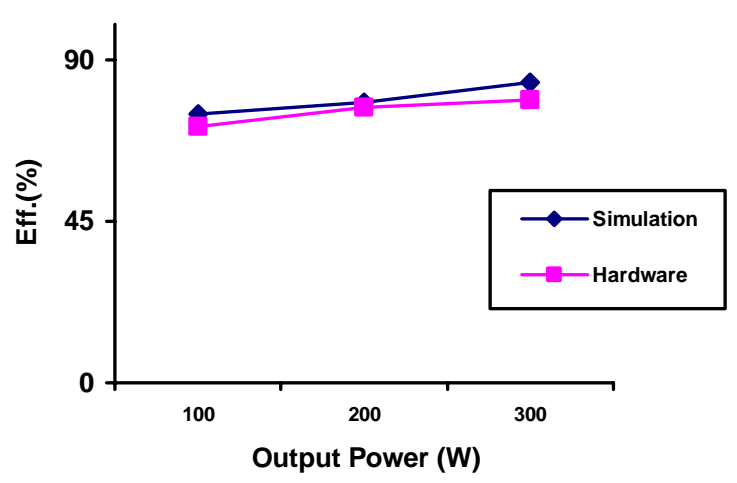

(b)

Figure 7. Experimental results for (a) input power various with output power, (b) Output Power various with Efficiency

As shown in Figure.7. (a) - (b) the control characteristics are observed to closely match the theoretical curve, and the output power is seen to be nearly independent of load. The conversion efficiency of the prototype is measured by varying the pulse to the inverter to vary the output power under different loading conditions at $100 \mathrm{~V}$ input de voltage. The plots of experimental efficiency as a function of the output power are shown in Figure.7 (b).The full load conversion efficiency of the prototype is measured to be 0.76 and it remains above 0.80 for $100-300 \mathrm{~W}$ output power. Out of total $40 \mathrm{~W}$ power loss in the prototype operating at $300 \mathrm{~W}$, a major portion $(\approx 20 \mathrm{~W})$ is estimated to occur in the MOSFETs and diodes. The rest of losses can be attributed largely to the core and also there will be a winding loss in transformer and resonant inductor.

\section{Conclusion}

A modified series parallel resonant converter which employs a LLC-T resonant converter circuit has been simulated for estimating the performance for various load conditions. It has been found from the simulated results that the closed loop controller provides better control strategies. It is concluded that the FLC based LLC-T resonant converter circuit provide load independent 
operation and better voltage regulation. The switching power losses are minimized and hence the ripple factors are less. A prototype $300 \mathrm{~W}, 100 \mathrm{kHz}$ converter was designed. The experiment results are compared with the simulation results. The simulation results agree with the experimental results. This modeling is expected to provide more ideas for the engineers to design various converters for different applications such as magnet power supply, capacitor charging power supply, and airborne applications.

\section{References}

Bhat A.K.S., 1997.Analysis and design of a fixed-frequency LCL-type series resonant converter with capacitive output filter, IEE PROC-Circuits Devices syst, Vol.144, No.2, April, pp. 97-103.

Bhat A.K.S.,1994a.Frequency domain analysis of a fixed-frequency LCL type series-resonant converter, Int. Power Electronics Motion and Control Conf., Beijing, China, pp. 354-359, June.

Bhat A.K.S., 1993.Analysis and design of a series parallel resonant converter, IEEE Trans. Power Electron, Vol. 8, pp.1-11, January.

Bhat A.K.S., 1994b. Analysis and design of LCL-type series resonant converter, IEEE INTELEC, pp.172-178, May.

Borage M., Tiwari S. and Kotaiah S., 2005. Analysis and design of an LCL-T resonant converter as a constant-current power supply, IEEE Transactions on Industrial Electronics, Vol. 52, No. 6, December. pp. 1547-1554.

Borage M.B., Nages K.V., Bhatia M.S. and Tiwari S.,2009. Characteristics and design of an asymmetrical duty-cycle-controlled LCL-T resonant converter, IEEE Transactions on Power Electronics, Vol. 24, No.10, pp. 2268 - 2275.

Belaguli, V. Bhat, A.K.S. Vijayakumar Belaguli, and Bhat A.K.S., 2000.Series-parallel resonant converter operating in discontinuous current mode-analysis, design, simulation, and experimental results,IEEE Transactions on Circuits and System-I: Fundamental Theory and Applications, Vol. 47, No. 4, April., pp. 433 - 442

China C.L. and Sng K.K., 2009. A novel robust control method for the series-parallel resonant converter, IEEE Transactions on Power Electronics, Vol. 24, No.8, August.

Gu Y.. Lu Z. Hang L., Qian Z. and Huang G., 2005.Three-level LLC series resonant DC/DC converter, IEEE Transactions on Power Electronics, Vol.20, pp.781-789, July.

Lu B., Liu W., Liang Y., Lee F.C., Jacobus and Wyk D.V.,2006. Optimum design for LLC resonant converter, APEC 2006, pp. 533-538.

Nagarajan C. and Madheswaran M., 2010. Performance analysis of LCL-T resonant converter with fuzzy /PID controller using state space analysis, International Journal of Electronic Engineering Research, Vol.2 No. 1, pp. 51-70, May.

Prabhakar.M, Arulmaozhi S. and Kamaraj.V., 2009. Selection criteria and analysis of LCC resonant DC-DC converters for automotive application, Modern Applied Science, Vol.3, No.7, July.

Raju, G.S.N., Doradla, S., 1995. An LCL resonant converter with PWM control-analysis, simulation and implementation, IEEE Transaction on Power Electronics, Vol.10, No.2, March., pp. 164-174.

Biographical notes

C. Nagarajan received the B.E degree from K.S.Rangasamy College of Technology, affiliated to Madras University, during 1997-2001, India, and the M.Tech degree from the Vellore Institute of Technology, Vellore, Tamilnadu India, in 2004. He is currently working towards his doctoral degree at Bharath Institute of Higher Education and Research (BIHER) University, Chennai, India. He has been a member of the faculty at Centre for Advanced Research, Muthayammal Engineering College, Rasipuram, Tamilnadu, India since 2005. His research interests include fuzzy logic and neural network applications to power electronics and drives.

M. Madheswaran received the BE Degree from Madurai Kamaraj University in 1990, ME Degree from Birla Institute of Technology, Mesra, Ranchi, India in 1992, both in Electronics and Communication Engineering. He obtained his PhD degree in Electronics Engineering from the Institute of Technology,Banaras Hindu University, Varanasi, India, in 1999. At present he is a Principal of Muthayammal Engineering College, Rasipuram, India. He has authored over forty five research publications in international and national journals and conferences. His areas of interest are theoretical modeling and simulation of high-speed semiconductor devices for integrated optoelectronics application, Bio-optics and Bio-signal Processing. He was awarded the Young Scientist Fellowship (YSF) by the State Council for Science and Technology, TamilNadu, in 1994 and Senior Research Fellowship (SRF) by the Council of Scientific and Industrial Research (CSIR), Government of India in 1996. Also he has received YSF from SERC, Department of Science and Technology, Govt. of India. He is named in Marquis Who's Who in Science and engineering in the year 2006. He is a life member of IETE, ISTE and IE (India) and also a senior member of IEEE.

Received September 2010

Accepted November 2010

Final acceptance in revised form December 2010 